\title{
Evaluation of bioactivity of fucoidan from laminaria with in vitro human cell cultures (THP-1).
}

\section{Magdalena M. Stefaniak-Vidarsson'1, María Gudjónsdóttir'1, Gudrun Marteinsdottir²,3, Olafur E. Sigurjonsson, ${ }^{4,5}$, Kristberg Kristbergsson ${ }^{1,3 *}$}

${ }^{1}$ Faculty of Food Science and Nutrition, School of Health Sciences, University of Iceland; ${ }^{2}$ School of Engineering and Natural Sciences, University of Iceland; ${ }^{3}$ TARAMAR ehf, Innovation Centre Iceland, Reykjavik, Iceland; ${ }^{4}$ Blood Bank, Landspitali University Hospital, Reykjavik, Iceland; ${ }^{5}$ School of Science and Engineering, Reykjavik University, Reykjavik, Iceland.

Corresponding author: Kristberg Kristbergsson, $\mathrm{PhD}$, professor, Faculty of Food Science and Nutrition, School of Health Sciences, University of Iceland, Saemundargata 6, 101 Reykjavik, Iceland

Submission Date: June 29 ${ }^{\text {th }}$, 2017, Acceptance Date: September $27^{\text {th }}$, 2017, Publication Date: September $30^{\text {th }}, 2017$

Citation: Stefaniak-Vidarsson M.M., Gudjónsdóttir M., Marteinsdottir G., Sigurjonsson O.E., Kristbergsson K, Evaluation of bioactivity of fucoidan from luminaria with in vitro human cell cultures (THP-1). Functional Foods in Health and Disease 2017; 7(9): 688-701. https://doi.org/10.31989/ffhd.v7i9.373

\begin{abstract}
Background: Seaweeds represent one of the few remaining food sources available globally which are not being fully utilized or even over utilized. Kelps (Laminaria spp.) are one of the numerous species of brown seaweeds, a popular marine vegetable, which has been used as a source of iodine and minerals for centuries. Kelps contain anionic polysaccharides called fucoidans heteroglycans with $\mathrm{L}$ - fucose units. Their monosaccharide composition, physicochemical and bioactive properties vary between seaweed species. The objective of this work was to evaluate the bioactive properties of laminaria fucoidan (L. digitata and L. hyperborea) toward THP-1 macrophages, a human macrophage like cell line, and investigate its potential antioxidant and immunomodulatory characteristics.
\end{abstract}

Methods: THP-1 macrophages were incubated with five fucoidan concentrations. The Oxygen Radical Absorbance Capacity (ORAC) assay was determined for cell lysates and for the fucoidan extract, in addition to Total Polyphenol Content (TPC). Cytotoxicity of fucoidan was assessed by light microscopy, followed by XTT proliferation assay. Enzyme-linked immunosorbant assays (ELISA) were performed to determine concentrations of the secreted tumor necrosis factor $\alpha$ (TNF- $\alpha$ ), interleukin 6 (IL-6), and interleukin 10 (IL-10). 
Results: Fucoidan did not affect macrophage ability to scavenge oxygen radicals (ORAC) confirming its antioxidant properties toward activated macrophages. The laminaria fucoidan extract at $100 \mu \mathrm{g} / \mathrm{ml}$ concentration lowered macrophage viability. Lower concentrations of laminaria fucoidan did not have impact on cell viability. Very low concentration of fucoidan at 0.1 $\mu \mathrm{g} / \mathrm{ml}$ triggered secretion of TNF- $\alpha$. However, IL -6 and interleukin IL-10 were expressed when concentration of applied fucoidan was $10 \mu \mathrm{g} / \mathrm{ml}$ indicating bioactivity of laminaria fucoidan through immunomodulatory actions.

Conclusion: The study demonstrated how laminaria fucoidan may have bioactive properties towards THP-1 macrophages. Changes in cytokine secretion between pro-inflammatory (TNF- $\alpha$, and $\mathrm{IL}-6$ ) and anti-inflammatory (IL-10) cytokines confirmed bioactivity of the laminaria fucoidan extracts.

Keywords: Seaweeds, Kelps, Laminaria, fucoidan, bioactivity, macrophages

\section{INTRODUCTION}

Seaweeds have been eaten as a food in Asia for centuries. Unsurprisingly, people in Western societies have increased seaweed consumption in recent years, likely due to the increased awareness of the pro-health properties of seaweeds. The term sea vegetables has been proposed [1]. The abundance of nutrients and active compounds in marine macro algae makes them interesting ingredients for a variety of food and cosmetic products.

Seaweeds are classified into three groups: red (Rhodophyta), brown (Phaeophyta), and green (Chlorophyta) based on their macro algae pigmentation. Brown seaweeds are a large group of marine algae (1500-2000 species worldwide). They are a recognized source of healthy food, packed with nutrients and bioactive compounds, including polysaccharides (alginates, fucoidans, and laminarans), polyphenols (phlorotannins), minerals ( $\mathrm{Ca}, \mathrm{Fe}, \mathrm{Mg}$ ), vitamins ( $\mathrm{A}, \mathrm{B}_{1}, \mathrm{~B}_{2}, \mathrm{~B}_{3}, \mathrm{~B}_{5}$, $\mathrm{B}_{12}, \mathrm{C}, \mathrm{D}, \mathrm{E}$, and folic acid), and polyunsaturated fatty acids (omega-3 and omega-6) [2, 3]. In Asia, seaweeds are part of a daily diet while in Western countries brown seaweeds have been used more for extraction and isolation of compounds for their nutraceutical and therapeutical properties $[4,5]$. The number of seaweed bioactive components is abundant; during the past decade, special attention has been placed on seaweed derived polysaccharides, especially in the fields of pharmacy and biochemistry [5].

Kelps are brown macro algae that contain approximately 30 genera. They are found in the cold seas, close to the coastlines. In China, kelps were used as early as 3600 years BC to treat goiter and thyroid condition caused by iodine deficiency [6]. In Europe and especially in Scotland, kelps were used as a source of alkali, a key ingredient in the production of soap and glass until the $19^{\text {th }}$ century [7]. For example, ingredients derived from kelps still find applications in foods (alginates) and as thickening agents in jellies or ice-creams. The most interesting compounds, which still require better understanding, are called fucoidans. Fucoidans (fucans) are acidic polysaccharides occurring exclusively in brown algae [8]. Fucoidans are predominantly $\alpha(1 \rightarrow 2)-$ linked branched heteroglycans, which may contain a sulfate ester group at $\mathrm{C}_{3}$, and are mainly composed of L-fucose, but other carbohydrates, such as uronic acid, galactose, xylose, and sulfated fucose, are also present in the fucoidan structure [2]. The monosaccharide composition, molecular weight (approximately 100 to $1600 \mathrm{kDa}$ ), and bioactivity vary between seaweed species, 
making seaweeds a very intriguing research subject with many questions yet to be answered [8, 9]. Fucoidans have been shown to exhibit versatile bioactive properties, such as antioxidant [10], anti-inflammatory [5], and immunomodulatory, including anticancer activity [11]. Despite the progress in determining properties of various fucoidans, information on the properties of fucoidan from Laminaria digitata and Laminaria hyperborea have not been reported [12].

Many physicochemical assays have been used to understand the bioactivity of marine derived compounds $[13,14]$. The relationship between results from many of the chemical methods being used for this purpose and actual bioactivity and function in the human body may be questioned. It would therefore be beneficial for further understanding the bioactive properties of fucoidans to use methods which come closer to the biochemistry taking place within the human body. One approach towards this objective is to use in vitro cell cultures, with human cell lines, which should give a more realistic model of how the compounds may behave within the body. Experiments performed with in vitro cell models combine fields of research from biochemistry, immunology, food and nutritional sciences, which may lead to a better understanding of fucoidans properties [15]. The THP-1 macrophage cell model is an in vitro method used in the investigation of the bioactivity of food derived compounds [16]. Macrophages that are derived from monocytes have the ability to remove pathogens and cellular debris using phagocytosis [17]. Macrophages also secrete a wide variety of signaling proteins, like cytokines and growth factors, that can trigger cellular responses [18]. The tumor necrosis factor $-\alpha(\mathrm{TNF}-\alpha)$ is an early response cytokine, which triggers macrophage movement toward stimuli (chemotaxis), which leads to increased phagocytosis (pathogen removal) and cytotoxicity (toxicity toward cells) [19]. In response to TNF- $\alpha$, another cytokine called interleukin-6 (IL-6) starts to be secreted by the macrophage cells. IL-6 has been recognized as a cytokine involved in inflammation, but also as a cytokine with regenerative and anti-inflammatory properties [20]. However, interleukin-10 (IL-10) suppresses the activity of monocytes and macrophages activity, and downregulates secretion of selected cytokines, such as TNF $-\alpha$ and IL -6 , which are involved in inflammatory processes [21]. IL-10 is secreted to limit the release of TNF- $\alpha$ and IL-6 and to decrease inflammatory responses [22]. Secretion of cytokines may indicate bioactivity of applied compounds towards human macrophages. To the best of our knowledge, fucoidans derived from Laminaria digitata and Laminaria hyperborea have not been studied with respect to their bioactivity using in vitro human cellular models. The purpose of this research was to test and evaluate the potential bioactivity of fucoidan derived from Laminaria digitata and Laminaria hyperborea, to determine the properties of fucoidan extracts of various concentrations towards human THP-1 macrophages, as an indication of their bioactivity.

\section{MATERIALS AND METHODS:}

\section{Fucoidan}

Fucoidan from Laminaria digitata and Laminaria hyperborea (\#PSa 13) was purchased from Glycomix Ltd., The Science and Technology Centre (Reading, UK). The fucoidans were obtained by hot water extractions, performed to isolate polysaccharides (alginates, fucoidans, and laminarans) from the seaweed tissue of two similar phenotypical brown seaweeds: Laminaria digitata and Laminaria hyperborea. The ratio between these two seaweed species was not known, since these species are difficult to distinguish. Alginates were removed from the solution with precipitation of calcium ions. Laminarans were removed through the use of laminaranase enzyme, 
leaving a crude fucoidan extract, which was then purified with activated charcoals to remove any colored components like tannins. The fucoidan from Laminaria in this study was selected due to the mild preparation method used. Higher yields of fucoidans may be obtained with the aid of more aggressive extraction methods like organic solvents but were avoided as the fucoidan was applied directly to cells (macrophages) which are known to be very sensitive. Therefore, it was essential to use compounds free of organic residues and other chemical impurities. Fucoidans obtained by hot water extractions are also more desirable in functional foods and high-quality cosmetics.

\section{Reagents}

The following reagents were used: Folin \& Ciocalteu's phenol reagent, anhydrous sodium carbonate, gallic acid, fluorescein, 2,2'-Azobis(2-methylpropionamidine) dihydrochloride (AAPH), ( \pm )-6-Hydroxy-2,5,7,8-tetramethylchromane-2-carboxylic acid (Trolox®) (\#238813), phorbol 12 - myristate 13 - acetate(PMA) and 2- mercaptoethanol were purchased from Sigma Aldrich Produktions GmbH (Steinheim, Germany). Sterile $10 \mathrm{mM}$ phosphate buffer saline (PBS) without magnesium and calcium, $\mathrm{pH}=7.4$, RPMI 1640- GlutaMAX ${ }^{\mathrm{TM}}$ culture medium and Trypan Blue 0.4\% staining solution, Penicillin -Streptomycin, Fetal Bovine Serum (FBS) were purchased from Invitrogen (Paisley, UK). 2,3-Bis (2-methoxy-4-nitro-5-sulfophenyl)-2Htetrazolium-5-carboxanilide (XTT) proliferation assay from (ATCC, Manassas, VA, USA). Human ELISA TNF $-\alpha$, IL-10, IL -6 and ELISA buffer kit were purchased from Peprotech EC Ltd. (London, UK).

\section{Cell cultures}

THP-1 monocytic cell line was purchased from LGC Standards GmbH (Wesel, Germany). Cells were cultured in RPMI 1640 with GlutaMAX ${ }^{\mathrm{TM}}$ medium, supplemented with penicillin/streptomycin, 10\% fetal bovine serum (FBS), and $50 \mu \mathrm{M} 2$-mercaptoethanol in the incubator (Thermo Forma 311 Model, Thermo Electron Corporation, Marietta, USA) under controlled conditions $\left(37^{\circ} \mathrm{C}, 5 \% \mathrm{CO}_{2}, 95 \%\right.$ air humidity). The experiments were carried out in triplicate for each fucoidan concentration $(0,0.1,1,10$, and $100 \mu \mathrm{g} / \mathrm{mL})$. All repetitions were performed on high quality cells (early passages 8-10). Cells were seeded into 6-well Corning Primaria culture plates (Beckton Dickinson Labware Europe, Le Pont de Claix, France) with a density of $0.6 \times 10^{6}$ cell $/ \mathrm{mL}$. Before seeding, the cell's viability was confirmed by Trypan Blue exclusions, using a hematocytometer and was shown to be at least $98 \%$. THP-1 monocytes were differentiated into macrophages by $72 \mathrm{~h}$ incubation in complete growth medium with $200 \mathrm{ng} / \mathrm{mL}$ PMA. After incubation, cells were washed twice with pre-warmed $10 \mathrm{mM}$ phosphate buffer saline (PBS) without magnesium and calcium, $\mathrm{pH}=7.4$. Laminaria fucoidan was dissolved in culture medium, placed under UV light for $20 \mathrm{~min}$ and centrifuged at $3000 \mathrm{rpm}$ for $10 \mathrm{~min}$ (Thermo Scientific Heraeus Multifuge X3, Thermo Electron LED GmbH, Osterode, Germany). The supernatant was applied to the cells at concentrations $0,0.1,1,10$, and $100 \mu \mathrm{g} / \mathrm{mL}$. After $24 \mathrm{~h}$ incubation the medium was collected and placed at $-80^{\circ} \mathrm{C}$ for further analysis (ELISA). The plate with attached macrophages was placed on ice, and ice cold 10mM PBS was added to the wells to improve macrophage detachment. Attached macrophages were gently harvested by rubber policemen, and later sonicated in cold water in a sonicator bath (TI-H-20, Elma, Singen/Htw., Germany) for $30 \mathrm{~min}$. 


\section{Cell viability assessment}

THP-1 cells were seeded on a 96-welled, flat bottomed and transparent microplates (Beckton Dickinson Labware Europe, Le Pont de Claix, France) at a density of 5x10 4 cells/well. THP-1 monocytes were differentiated into macrophages by $72 \mathrm{~h}$ incubation with $200 \mathrm{ng} / \mathrm{mL}$ PMA. Fucoidan was added to the differentiated cells at five different concentrations: $0,0.1,1,10$, and $100 \mu \mathrm{g} / \mathrm{mL}$ followed by $24 \mathrm{~h}$ incubation. The cytotoxicity of laminaria fucoidan was assessed by light microscopy (Leica Microsystems Wetzlar GmbH, Wetzlar, Germany) followed by XTT proliferation assay performed according to the manufacturer's instructions (ATCC, Manassas, VA, USA).

\section{Estimation of Total Polyphenol Content (TPC) in laminaria fucoidan}

Estimation of TPC in laminaria fucoidan was necessary to evaluate whether phlorotannins (polyphenols) were present in the laminaria fucoidan extract, which could possibly enhance the antioxidant and bioactive properties of the fucoidan being tested. As previously reported, seaweed polyphenols are strong antioxidants and bioactive compounds [23]. Therefore, their presence in laminaria fucoidan could have an impact on the antioxidant and bioactive properties of their extracts.

TPC was determined by the modified method of N Turkmen, Y Velioglu, F Sari and G Polat [24]. A $10 \mathrm{mg}$ sample of laminaria fucoidan was dissolved in $1 \mathrm{~mL}$ of ion exchanged water. From there $20 \mu \mathrm{L}$ aliquots, together with $20 \mu \mathrm{L}$ of gallic acid standards, were added and mixed with 100 $\mu \mathrm{L}$ of Folin \& Ciocalteu's phenol reagent (10\% in distilled water) in a PureGrade 96-well flat bottom transparent microplate (Brand $\mathrm{GmbH}+\mathrm{CO}$ KG, Wertheim, Germany). After 5 minutes of mixing, $80 \mu \mathrm{L}$ of $7.5 \% \mathrm{Na}_{2} \mathrm{CO}_{3}$ solution was added to the solution. The plate was incubated for 30 $\min$ at $40^{\circ} \mathrm{C}$, and then the absorbance was measured in a Multiskan Spectrum spectrometer (Thermo Scientific, USA) at $700 \mathrm{~nm}$. The total polyphenol content was determined from a standard curve, and expressed as grams of gallic acid equivalent (GAE) per $100 \mathrm{~g}$ of dry extract.

\section{Determination of Oxygen Radical Absorbance Capacity (ORAC)}

ORAC was determined both for cell lysates and laminaria fucoidan. ORAC assays for cell lysates were performed according to a method described by F Ganske and EJ Dell [25], and modified as described in M Aurich, G Paglia, Ó Rolfsson, S Hrafnsdóttir, M Magnúsdóttir, M Stefaniak, B Palsson, RT Fleming, and I Thiele [26]. The laminaria fucoidan extract was dissolved in $10 \mathrm{mM}$ PBS at pH 7.4, and centrifuged at $3500 \mathrm{rpm}$ for $10 \mathrm{~min}$ (Centrifuge 5417R, Eppendorf AG, Hamburg, Germany). Cell lysates were stored in $10 \mathrm{mM}$ PBS buffer at $-20^{\circ} \mathrm{C}$ for no longer than 1 day, and thawed on ice before measurements to minimize the risk of oxidation. ORAC assays were performed in 96-well, transparent, flat bottom microplates (Brand $\mathrm{GmbH}+\mathrm{CO} \mathrm{KG}$, Wertheim, Germany) in a SpectraMax M3 Multi-Mode Microplate Reader (Molecular Devices, CA, USA). All reagents and samples were prepared in $10 \mathrm{mM}$ PBS ( $\mathrm{pH}=7.4)$ solution. A multichannel pipettor was used to dispense $150 \mu \mathrm{L}$ of $10 \mathrm{nM}$ fluorescein in triplicate into the microplate wells. Then $25 \mu \mathrm{l}$ of 0 to $50 \mu \mathrm{M}$ of Trolox standard, or sample, were added to the wells. The plate was placed on ice and $25 \mu$ of ice cold 120nM 2,2'-Azobis (2-methylpropionamidine) dihydrochloride (AAPH) was quickly added. The plate was immediately placed inside the measuring device which was preheated to $37^{\circ} \mathrm{C}$ (Multi Mode Microplate Reader), and the 
measurement program was initialized with $15 \mathrm{sec}$ of shaking before measurement. Readings were performed with $1 \mathrm{~min}$ intervals for $80 \mathrm{~min}$ at $37^{\circ} \mathrm{C}$; at $485 \mathrm{~nm}$ excitation and $580 \mathrm{~nm}$ emission. A $515 \mathrm{~nm}$ cut off filter was used for emission for signal improvement. The SoftMax Pro software (Molecular Devices, CA) was used to calculate the ORAC values. ORAC values were expressed as $\mu \mathrm{Mol}$ of Trolox Equivalent (T.E)/g of dry extract (fucoidan), or $\mu \mathrm{M}$ of T.E $/ 110^{6}$ cells (cell lysates), using the calibration curve for Trolox ${ }^{\circledR}$.

\section{Enzyme-linked immunosorbent assay (ELISA)}

Medium collected from the cell cultures was centrifuged (Centrifuge 54115R, Eppendorf AG, Hamburg, Germany) at $3500 \mathrm{rpm}$ for $10 \mathrm{~min}$ to remove cellular debris, and then stored at $-80^{\circ} \mathrm{C}$ until further analysis. To determine the secretion of cytokines (TNF- $\alpha$, IL-6, IL-10) Enzyme Linked Immunosorbent Assay (ELISA) was performed according to the manufacturer's instructions (Peprotech EC Ltd., London, UK).

\section{Statistical analysis}

Data was reported as the mean of the experiments \pm standard error (SEM). Each experimental condition was performed in triplicate. Data were analyzed by one-way analysis of variance (ANOVA), using the Sigma Stat 9.0 program from Systat Software (Systat Software, San Jose, CA, USA). Significant differences in the means between groups were calculated using the HolmSidak multiple comparison.

\section{RESULTS AND DISCUSSION}

\section{Cell Viability Assessment}

No morphological changes were observed in differentiated macrophages with added fucoidan at 0.1 to $10 \mu \mathrm{g} / \mathrm{mL}$ with microscopic assessment (Fig. 1a). However, there was a decreased number of cells and changes in the cell membrane integrity at $100 \mu \mathrm{g} / \mathrm{mL}$ concentration of fucoidan. Analysis by the XTT proliferation assay confirmed the microscopic observations. The cell viability varied from $86 \pm 2 \%$ to $61 \pm 2 \%$ at 0.1 to $10 \mu \mathrm{g} / \mathrm{mL}$ laminaria fucoidan concentrations, compared to $100 \%$ viability for the control group (without added fucoidan). A significant decrease in cell viability was only observed for fucoidan at $100 \mu \mathrm{g} / \mathrm{mL}$ concentration $(\mathrm{p}<0.001)$ compared to the control. The cell viability was not significantly affected at the other applied concentrations ( 0.1 to $10 \mu \mathrm{g} / \mathrm{mL}$ ) compared to the control ( $\mathrm{p}>0.01$ ) (Fig. 1b). The data indicated that fucoidan from laminaria did not impair macrophage viability at 0.1 to $10 \mu \mathrm{g} / \mathrm{mL}$, but at $100 \mu \mathrm{g} / \mathrm{mL}$ concentration there was a significant decrease in cell viability (Fig.1b). As mentioned above, activated macrophages generate ROS, which may affect pro-inflammatory (TNF- $\alpha$ and IL-6), and antiinflammatory (IL-10) cytokine secretion, in addition to affecting the cellular capacity to scavenge free radicals, which may negatively affect macrophages viability as a consequence of oxidative stress. However, the ORAC values for the cell lysates indicated antioxidant properties of laminaria fucoidan towards the cells, which may have been protected from the toxic ROS accumulation. This ROS accumulation in the cellular matrix may have been the reason for the decreased cell viability at $100 \mu \mathrm{g} / \mathrm{mL}$ concentration of the laminaria fucoidan. 


\section{Determination of Total Polyphenol Content (TPC) in laminaria fucoidan}

The Total Polyphenol Content (TPC) in the laminaria fucoidan extract was $27 \pm 11 \mathrm{mg} \mathrm{GAE} / 100$ g. Fucoidan is an aliphatic polysaccharide; therefore, gallic acid was selected as a standard to determine the polyphenol compounds in the fucoidan extracts [27]. The fucoidan was derived from two seaweed species: Laminaria digitata and Laminaria hyperborea. To the best of our knowledge, there is no published research data available on the TPC content in fucoidan extracts obtained by the same or similar methods that were used in this study. It is apparent that the yield of polyphenols from the water-enzyme extraction method used in this study is lower than what may be obtained with organic solvents. For example, the TPC content in methanol extracts of L.digitata has been previously estimated by S Cox, N Abu-Ghannam, and S Gupta [28] to be 38 mg GAE/g extract. According to the data reported by T Wang, R Jónsdóttir, and G Ólafsdóttir [14], TPC content in both L.digitata and L.hyperborea in acetone and water extracts showed that old blades (leaf like structures) of L. hyperborea are 13-14 times higher in TPC content compared to L. digitata (Phloroglucinol Equivalent (PGE)/100g extract)). However, the water-enzyme extracts were less toxic to the human cell cultures used for estimating bioactivity and may thereby be considered a more environmentally friendly or "more green" method. They will also likely render products with higher acceptability in high quality foods and functional foods.

a)

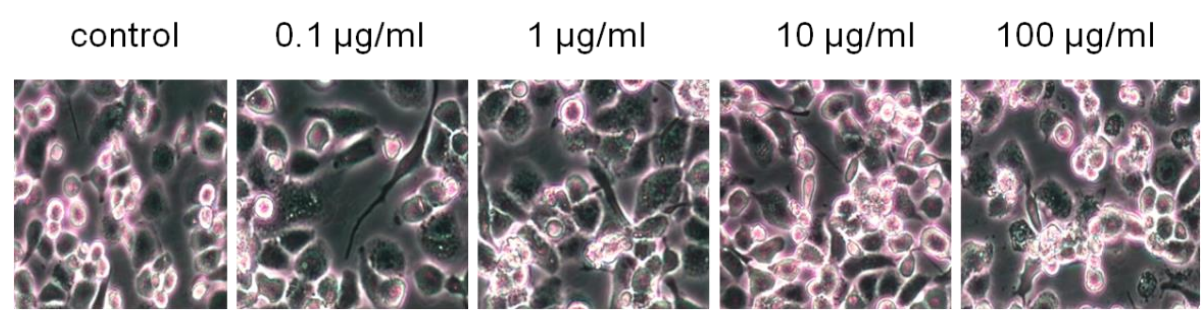

b)

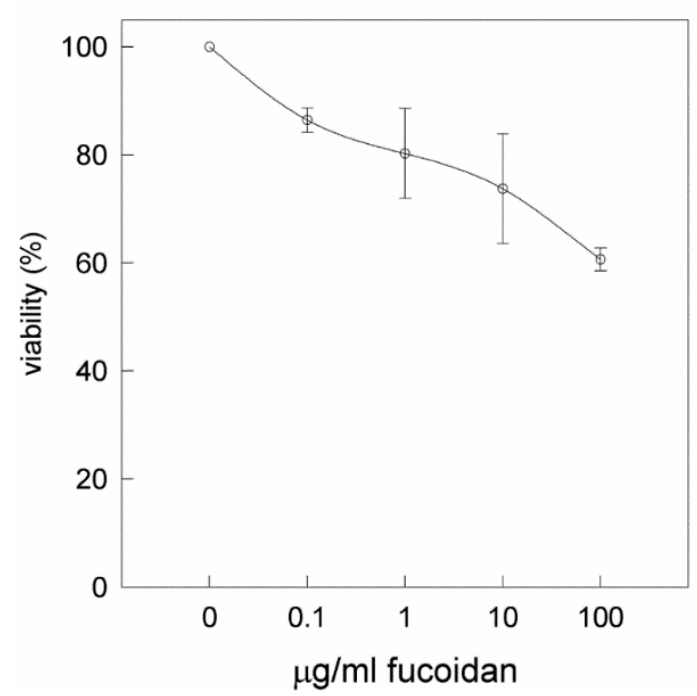

Figure 1. Fucoidan cytotoxicity toward macrophages. a) Light microscopy assessment of macrophages after $24 \mathrm{~h}$ incubation with fucoidan from laminaria at 40x magnification. b) Proliferation of cells with XTT proliferation assay after $24 \mathrm{~h}$ incubation. Error bars are standard error $(n=3)$. 


\section{Antioxidant properties of laminaria fucoidan (ORAC)}

The Oxygen Radical Absorbance Capacity of laminaria fucoidan was $1113 \pm 3 \mu \mathrm{M}( \pm)-6-$ Hydroxy-2,5,7,8-tetramethylchromane-2-carboxylic acid (Trolox Equivalent) (T.E)/ g in the dry laminaria fucoidan extracts, indicating antioxidant properties of laminaria fucoidan. The ORAC values for laminaria fucoidan were similar to values observed for water and $70 \%$ acetone extracts of Laminaria hyperborea, but not as high as what was previously described for extracts derived from Fucus vesiculosus $(2567 \mu \mathrm{M}$ T.E/g) [14]. However, the laminaria fucoidan extract used in this study was not extracted with organic solvents but with a milder water-enzyme method. Therefore, the ORAC values were likely not at their highest. For example, if the extracts would have been made with organic solvents like acetone. Another reason for selecting fucoidan laminaria as a food compound over bladder wrack (Fucus vesiculosus) is the smell and taste of kelps, which is salty and pleasant compared to the unpalatable smell and flavor of bladder wrack. This factor makes kelps a more desirable food component than bladder wrack although it may contain lower concentrations of antioxidants.

\section{Oxygen Radical Absorbance Capacity (ORAC) in cell lysates}

The ability of macrophage cells to scavenge reactive oxygen species (ROS) was determined and was $485 \pm 21$ for the control group and $573 \pm 24,428 \pm 31,457 \pm 19$ and $427 \pm 16$ for fucoidan of concentrations of $0.1,1,10$, and $100 \mu \mathrm{g} / \mathrm{mL}$ respectively. The results did not significantly vary between tested fucoidan groups $(\mathrm{p}=0.048)($ Fig.2). The observed results may suggest that fucoidan did not affect the cellular ability to scavenge oxygen radicals, and furthermore may have minimized the accumulation of reactive oxygen species (ROS) in macrophages [29]. Intracellular ROS accumulation is known to increase the risk of oxidative stress which can lead to cell damage, lysis, or even cell apoptosis (programmed death) in addition to modulatory actions in inflammatory processes [30]. Therefore, we hypothesize that the accumulation of ROS may have had a serious impact on cellular ability to scavenge ROS, negatively affecting the oxygen radical absorbance capacity (ORAC) of the cells. This could possibly result in decreased values for ORAC in cell lysates. In this study, ORAC values in macrophage lysates after application of laminaria fucoidan were not significantly decreased, which may suggest that laminaria fucoidan could have protected the cells from excessive accumulation of ROS and oxidative stress, and as a result confirming the antioxidant properties of laminaria fucoidan.

\section{Cytokine secretion}

TNF- $\alpha$ and IL -6 are cytokines involved in pro-inflammatory responses, while IL-10 is known for its anti-inflammatory properties [31-33]. The current study demonstrates that even the lowest concentration of fucoidan $(0.1 \mu \mathrm{g} / \mathrm{mL})$ increased the secretion of TNF- $\alpha$ by macrophages to 658 $\pm 58 \mathrm{pg} / \mathrm{mL}$ compared to the control group at $156 \pm 22 \mathrm{pg} / \mathrm{mL},(\mathrm{p} \leq 0.05)$. The TNF- $\alpha$ values were also significantly increased with increased fucoidan concentrations resulting in $551 \pm 98 \mathrm{pg} / \mathrm{mL}$, $893 \pm 24 \mathrm{pg} / \mathrm{mL}$, and $1895 \pm 55 \mathrm{pg} / \mathrm{mL}$ for 1,10 , and $100 \mu \mathrm{g} / \mathrm{mL}$ respectively (p<0,001) (Fig. 3). TNF $-\alpha$ is known for its regulatory properties toward other cytokines, such as IL -6 and several growth factors, including the transforming growth factor $\beta$ (TGF- $\beta$ ) and the platelet derived growth factor (PDGF) or hormones (adrenaline) [19]. TNF- $\alpha$ plays a key role in the protection against infection modulating inflammatory responses by increasing the migration of phagocytes 
into tissue [34]. However, excessive secretion of this very potent cytokine may lead to oxidative stress and induce inflammation [35]. As expected, the secretion of TNF- $\alpha$ was followed by the secretion of another cytokine IL-6.

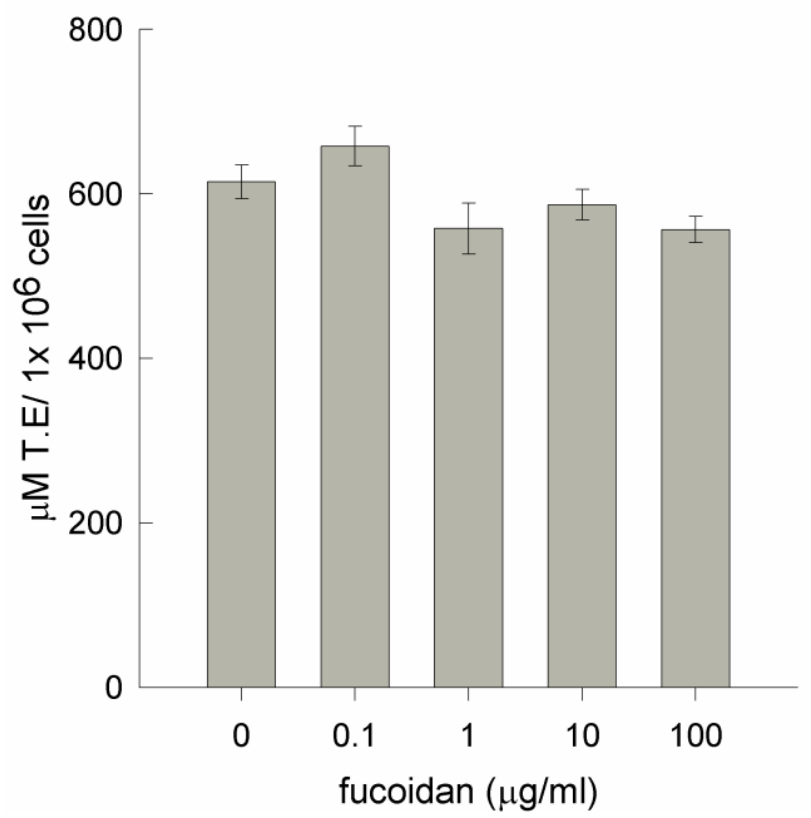

Figure 2. Oxygen Radical Absorbance Capacity (ORAC). ORAC values were determined in cell lysates after $24 \mathrm{~h}$ incubation with fucoidan and expressed as $\mu \mathrm{M}$ Trolox ${ }^{\circ E q u i v a l e n t}$ (T.E) $/ 1 \mathrm{x}$ $10^{6}$ cells. Error bars are standard errors $(n=3)$.

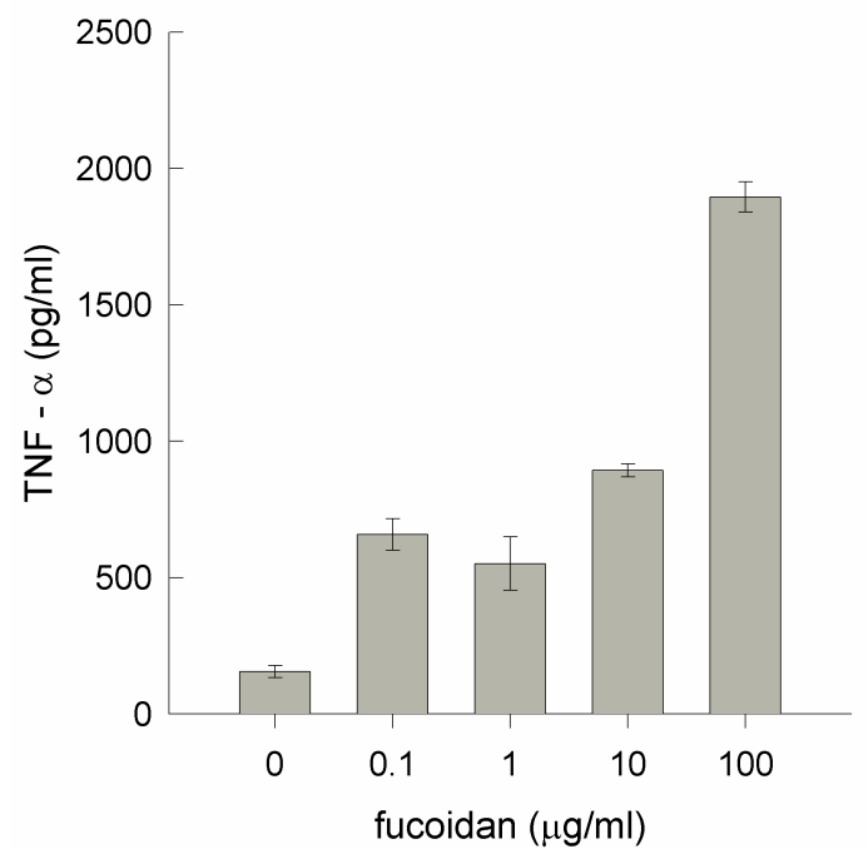

Figure 3. Secretion of TNF $-\alpha$. Levels of $\mathrm{TNF}-\alpha$ are expressed as $\mathrm{pg} / \mathrm{ml}$. Error bars are standard errors. $(n=3)$. 
Fucoidan did not induce IL -6 secretion at the lower fucoidan concentrations tested at 0.1 and $1 \mu \mathrm{g} / \mathrm{mL},(\mathrm{p}>0.1$ ), but increased the levels of IL -6 significantly to $237 \pm 7$ and $819 \pm 14$ when applied at 10 and $100 \mu \mathrm{g} / \mathrm{mL}$ compared to the control group at $5.5 \pm 1.4$ (p<0.001) (Fig. 4). Similarly to TNF- $\alpha$, IL -6 is necessary for the maintenance of life functions, but its prolonged elevated levels may lead to the development of inflammation [36]. Moreover, high secretion of IL-6 is directly linked to toxicity due to the endotoxin contamination of biological materials that have been applied to cells [37].

Interleukin-10 (IL-10) is an anti - inflammatory cytokine whose secretion is regulated by proinflammatory cytokines, such as TNF- $\alpha$ and IL -6 [38]. In response to the presence of TNF- $\alpha$ and IL-6, the secretion of the anti-inflammatory cytokine IL -10 was observed at very low levels in the laminaria fucoidan extract concentrations at 0.1 and $1 \mu \mathrm{g} / \mathrm{mL}$ at $75 \pm 4 \mathrm{pg} / \mathrm{mL}$ and $69 \pm 15$ respectively, but was not significantly different from the control group at $5.4 \pm 1.9 \mathrm{pg} / \mathrm{mL}(\mathrm{p}>0.1)$. However, the secretion of IL-10 increased significantly $(\mathrm{p}<0.001)$ to $378 \pm 10$ when the concentration of laminaria fucoidan was increased to $10 \mu \mathrm{g} / \mathrm{mL}$ and jumped to $1900 \pm 73 \mathrm{pg} / \mathrm{mL}$ at $100 \mu \mathrm{g} / \mathrm{mL}$ of fucoidan extract (Fig. 5). Previous research data indicated that simultaneous secretion of TNF- $\alpha$, IL-6, and IL-10 may lead to immune stimulation [39]. The observed pattern of cytokine secretion may suggest immuno-stimulant properties of laminaria fucoidan towards THP-1 macrophages. However, it is known that the activated or/and immuno-stimulated macrophages are able to generate reactive oxygen species (ROS), where excessive accumulation may induce oxidative stress, decreasing cellular capacity to scavenge free radicals, impairing cellular membrane integrity or even leading to apoptotic cell death as a result of oxidative stress experienced by the cells $[40,41]$.

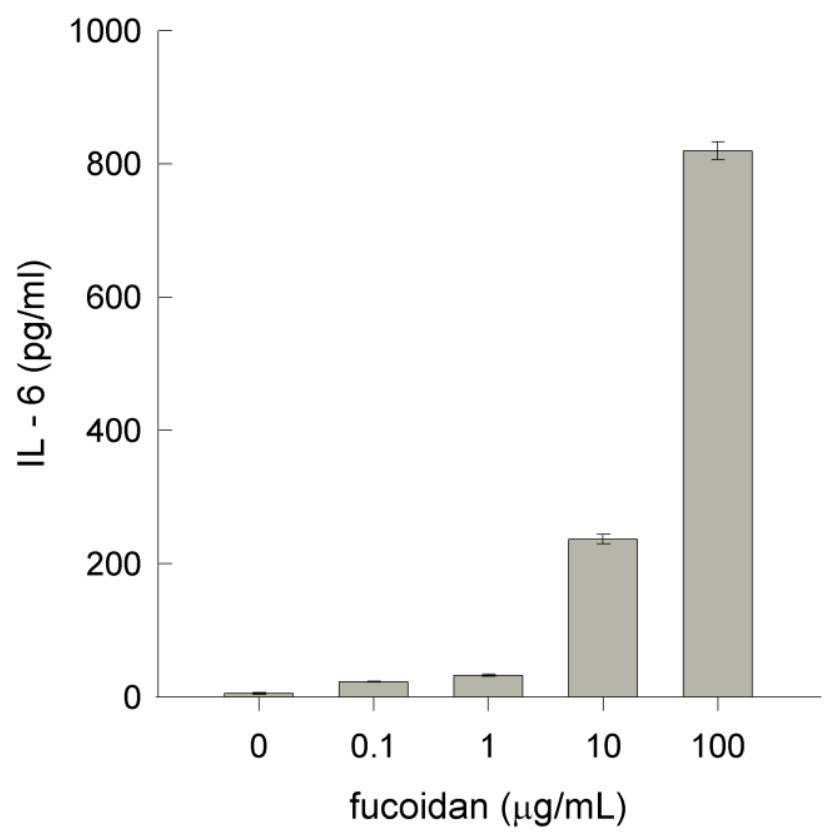

Figure 4. Secretion of IL -6 . Levels of IL -6 are expressed as $\mathrm{pg} / \mathrm{ml}$. Error bars are standard errors $(n=3)$. 


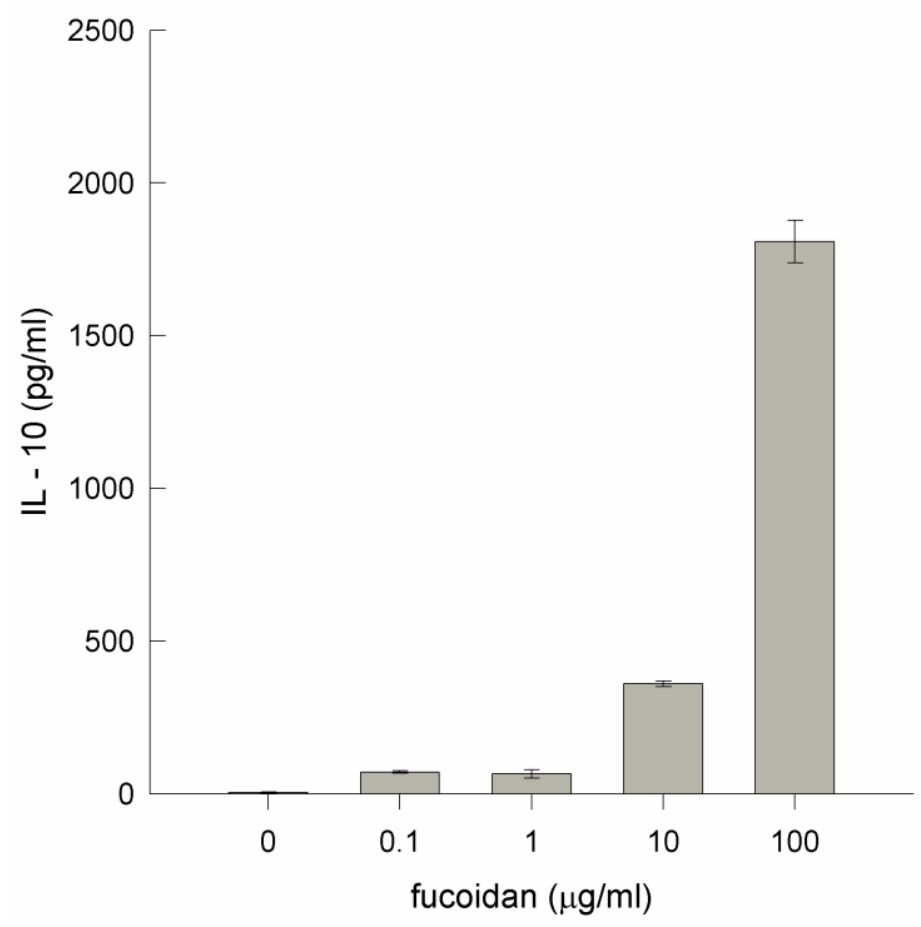

Figure 5. Secretion of IL - 10. Levels of IL - 10 are expressed as pg/ml. Error bars are standard errors $(n=3)$.

\section{CONCLUSIONS}

In this study, it was shown that laminaria fucoidan may have bioactive properties towards THP-1 macrophages. Changes in cytokine secretion between pro-inflammatory (TNF- $\alpha$, and IL-6) and anti-inflammatory (IL-10) cytokines confirmed the bioactivity of the laminaria fucoidan extracts. Laminaria fucoidan induced cellular responses even at very low concentrations. However, at this stage of the studies, protective properties of fucoidan against oxidative processes in macrophage membranes cannot be confirmed or excluded. Laminaria fucoidan did not affect cellular viability at the lower concentrations $(0.1$ to $10 \mu \mathrm{g} / \mathrm{mL})$, but a certain viability decrease was observed at 100 $\mu \mathrm{g} / \mathrm{mL}$. However, there is a need for further investigation to confirm or exclude the potential toxicity of laminaria fucoidan toward macrophages.

List of Abbreviations: THP-1, is a human monocytic cell line; ORAC, Oxygen Radical Absorbance Capacity; XTT proliferation assay, 2,3-Bis(2-methoxy-4-nitro-5-sulfophenyl)-2Htetrazolium-5-carboxanilide (XTT) proliferation assay; ELISA, Enzyme-linked immunosorbant assays; TPC, Total Polyphenol Content; TNF- $\alpha$, tumor necrosis factor $\alpha$; IL-6, interleukin 6; IL10, interleukin 10; PMA, phorbol 12 - myristate 13 - acetate; AAPH, 2,2'-Azobis(2methylpropionamidine) dihydrochloride; PBS, phosphate buffer saline; FBS, fetal bovine serum; GAE, gallic acid equivalent.

Competing Interests: The authors have no financial interests or conflicts of interest.

Authors' Contributions: All authors contributed to this study. 
Acknowledgments and Funding: The authors acknowledge the University of Iceland Research Fund for funding the project. and Dr. Ottar Rolfsson from the Center for Systems Biology, University of Iceland, Reykjavik, Iceland for access to the fluorimeter and research facility. The authors thank Dr. Olafur Fridjonsson and Dr. Varsha A. Kale at Matís ohf. Reykjavik, Iceland for donation of laminaria fucoidan.

\section{REFERENCES}

1. García-Sartal C, Barciela-Alonso MdC, Moreda-Piñeiro A, Bermejo-Barrera P: Study of cooking on the bioavailability of $\mathrm{As}, \mathrm{Co}, \mathrm{Cr}, \mathrm{Cu}, \mathrm{Fe}, \mathrm{Ni}, \mathrm{Se}$ and $\mathrm{Zn}$ from edible seaweed. Microchemical Journal 2013, 108(0):92-99.

2. Gupta S, Abu-Ghannam N: Bioactive potential and possible health effects of edible brown seaweeds. Trends in Food Science \& Technology 2011, 22(6):315-326.

3. van Ginneken V, Helsper J, de Visser W, van Keulen H, Brandenburg W: Polyunsaturated fatty acids in various macroalgal species from north Atlantic and tropical seas. Lipids in Health and Disease 2011, 10(1):104.

4. Mouritsen O, Williams L, Bjerregaard R, Duelund L: Seaweeds for umami flavour in the New Nordic Cuisine. Flavour 2012, 1(1):4.

5. Wijesinghe WAJP, Jeon Y-J: Biological activities and potential industrial applications of fucose rich sulfated polysaccharides and fucoidans isolated from brown seaweeds: A review. Carbohydrate Polymers 2012, 88(1):13-20.

6. Leung AM, Braverman LE, Pearce EN: History of U.S. Iodine Fortification and Supplementation. Nutrients 2012, 4(11):1740-1746.

7. Clow A, Clow NL: The natural and economic history of kelp. Annals of Science 1947, 5(4):297-316.

8. Gómez-Ordóñez E, Jiménez-Escrig A, Rupérez P: Molecular weight distribution of polysaccharides from edible seaweeds by high-performance size-exclusion chromatography (HPSEC). Talanta 2012, 93(0):153-159.

9. Cumashi A, Ushakova NA, Preobrazhenskaya ME, D'Incecco A, Piccoli A, Totani L, Tinari N, Morozevich GE, Berman AE, Bilan MI et al: A comparative study of the antiinflammatory, anticoagulant, antiangiogenic, and antiadhesive activities of nine different fucoidans from brown seaweeds. Glycobiology 2007, 17(5):541-552.

10. Rocha de Souza MC, Marques CT, Guerra Dore CM, Ferreira da Silva FR, Oliveira Rocha HA, Leite EL: Antioxidant activities of sulfated polysaccharides from brown and red seaweeds. Journal of Applied Phycology 2007, 19(2):153-160.

11. Kawashima T, Murakami K, Nishimura I, Nakano T, A. O: A sulfated polysaccharide, fucoidan, enhances the immunomodulatory effects of lactic acid bacteria. International Journal of Molecular Medicine 2012, 29:447-453.

12. Fitton JH: Therapies from Fucoidan; Multifunctional Marine Polymers. Marine Drugs 2011, 9(10):1731-1760.

13. Lim SJ, Wan Aida WM, Maskat MY, Mamot S, Ropien J, Mazita Mohd D: Isolation and antioxidant capacity of fucoidan from selected Malaysian seaweeds. Food Hydrocolloids 2014, 42, Part 2:280-288. 
14. Wang T, Jónsdóttir R, Ólafsdóttir G: Total phenolic compounds, radical scavenging and metal chelation of extracts from Icelandic seaweeds. Food Chemistry 2009, 116(1):240248.

15. Teruya T, Takeda S, Tamaki Y, Tako M: Fucoidan Isolated from Laminaria angustata var. longissima Induced Macrophage Activation. Bioscience, Biotechnology, and Biochemistry 2010, 74(9):1960-1962.

16. Chanput W, Mes JJ, Wichers HJ: THP-1 cell line: An in vitro cell model for immune modulation approach. International Immunopharmacology 2014, 23(1):37-45.

17. Kurosaka K, Watanabe N, Kobayashi Y: Production of Proinflammatory Cytokines by Phorbol Myristate Acetate-Treated THP-1 Cells and Monocyte-Derived Macrophages After Phagocytosis of Apoptotic CTLL-2 Cells. The Journal of Immunology 1998, 161(11):6245-6249.

18. Aderem A, Ulevitch RJ: Toll-like receptors in the induction of the innate immune response. Nature 2000, 406(6797):782-787.

19. Goswami B, Rajappa M, Mallika V, Shukla DK, Kumar S: TNF- $\alpha /$ IL-10 ratio and Creactive protein as markers of the inflammatory response in CAD-prone North Indian patients with acute myocardial infarction. Clinica Chimica Acta 2009, 408(1-2):14-18.

20. Scheller J, Chalaris A, Schmidt-Arras D, Rose-John S: The pro- and anti-inflammatory properties of the cytokine interleukin-6. Biochimica et Biophysica Acta (BBA) Molecular Cell Research 2011, 1813(5):878-888.

21. Burleson SCM, Fick RB, Mannie MD, Olmstead SG, Van Scott MR: Chapter 35 - The Immune Basis of Allergic Lung Disease A2 - Parent, Richard A. In: Comparative Biology of the Normal Lung (Second Edition). San Diego: Academic Press; 2015: 683719.

22. Stow JL, Ching Low P, Offenhäuser C, Sangermani D: Cytokine secretion in macrophages and other cells: Pathways and mediators. Immunobiology 2009, 214(7):601-612.

23. Li Y-X, Wijesekara I, Li Y, Kim S-K: Phlorotannins as bioactive agents from brown algae. Process Biochemistry 2011, 46(12):2219-2224.

24. Turkmen N, Velioglu Y, Sari F, Polat G: Effect of Extraction Conditions on Measured Total Polyphenol Contents and Antioxidant and Antibacterial Activities of Black Tea. Molecules 2007, 12(3):484-496.

25. Ganske F, Dell EJ: ORAC Assay on the FLUOstar OPTIMA to Determine Antioxidant Capacity. BMG LABTECH, Durham, USA 2006, 12.

26. Aurich M, Paglia G, Rolfsson Ó, Hrafnsdóttir S, Magnúsdóttir M, Stefaniak M, Palsson B, Fleming RT, Thiele I: Prediction of intracellular metabolic states from extracellular metabolomic data. Metabolomics 2014:1-17.

27. Bilan MI, Grachev AA, Ustuzhanina NE, Shashkov AS, Nifantiev NE, Usov AI: A highly regular fraction of a fucoidan from the brown seaweed Fucus distichus L. Carbohydrate Research 2004, 339(3):511-517.

28. Cox S, Abu-Ghannam N, Gupta S: An assessment of the antioxidant and antimicrobial activity of six species of edible Irish seaweeds. International Food Research Journal 2010, 17:205-220. 
29. Yu Q, Nie S-P, Wang J-Q, Yin P-F, Huang D-F, Li W-J, Xie M-Y: Toll-like receptor 4mediated ROS signaling pathway involved in Ganoderma atrum polysaccharideinduced tumor necrosis factor- $\alpha$ secretion during macrophage activation. Food and Chemical Toxicology 2014, 66(0):14-22.

30. Pfeiffer ZA, Guerra AN, Hill LM, Gavala ML, Prabhu U, Aga M, Hall DJ, Bertics PJ: Nucleotide receptor signaling in murine macrophages is linked to reactive oxygen species generation. Free Radical Biology and Medicine 2007, 42(10):1506-1516.

31. Barnes TC, Anderson ME, Moots RJ: The Many Faces of Interleukin-6: The Role of IL6 in Inflammation, Vasculopathy, and Fibrosis in Systemic Sclerosis. International Journal of Rheumatology 2011, 2011.

32. Jin J-O, Han X, Yu Q: Interleukin-6 induces the generation of IL-10-producing Tr1 cells and suppresses autoimmune tissue inflammation. Journal of Autoimmunity 2013, 40(0):28-44.

33. McLaren JE, Michael DR, Ashlin TG, Ramji DP: Cytokines, macrophage lipid metabolism and foam cells: Implications for cardiovascular disease therapy. Progress in Lipid Research 2011, 50(4):331-347.

34. Murphy K: Janeway's Immunology. Garland Science 2012, 8 th Edition.

35. Lee IT, Luo S-F, Lee C-W, Wang S-W, Lin C-C, Chang C-C, Chen Y-L, Chau L-Y, Yang C-M: Overexpression of HO-1 Protects against TNF- $\alpha$-Mediated Airway Inflammation by Down-Regulation of TNFR1-Dependent Oxidative Stress. The American Journal of Pathology 2009, 175(2):519-532.

36. Fernando MR, Reyes JL, Iannuzzi J, Leung G, McKay DM: The Pro-Inflammatory Cytokine, Interleukin-6, Enhances the Polarization of Alternatively Activated Macrophages. PLoS ONE 2014, 9(4):e94188.

37. Lieder R, Gaware VS, Thormodsson F, Einarsson JM, Ng C-H, Gislason J, Masson M, Petersen PH, Sigurjonsson OE: Endotoxins affect bioactivity of chitosan derivatives in cultures of bone marrow-derived human mesenchymal stem cells. Acta Biomaterialia 2013, 9(1):4771-4778.

38. Stenvinkel P, Ketteler M, Johnson RJ, Lindholm B, Pecoits-Filho R, Riella M, Heimburger O, Cederholm T, Girndt M: IL-10, IL-6, and TNF-alpha: Central factors in the altered cytokine network of uremia-The good, the bad, and the ugly. Kidney Int 2005, 67(4):1216-1233.

39. Burns JJ, Zhao L, Taylor EW, Spelman K: The influence of traditional herbal formulas on cytokine activity. Toxicology 2010, 278(1):140-159.

40. Lee JY, Kim Y-J, Kim HJ, Kim Y-S, Park W: Immunostimulatory Effect of Laminarin on RAW 264.7 Mouse Macrophages. Molecules 2012, 17(5):5404-5411.

41. de la Haba C, Palacio JR, Martínez P, Morros A: Effect of oxidative stress on plasma membrane fluidity of THP-1 induced macrophages. Biochimica et Biophysica Acta (BBA) - Biomembranes 2013, 1828(2):357-364. 